\title{
„Surrende Kreisel fördern nicht die Konzentration!"
}

\author{
Pokémon Go war gestern: Der neue Hype auf den Schulhöfen sind in \\ diesem Jahr die „Fidget Spinner“. Glaubt man den Herstellern, sollen \\ die bunten Kreisel die Konzentration fördern. Der Kinder- und Jugend- \\ psychiater Prof. Christoph Möller hält das jedoch für Humbug.
}

\section{$?$}

Prof. Christoph Möller Chefarzt Kinder- und Jugendpsychiatrie, Kinderund Jugendkrankenhaus Auf der Bult, Hannover

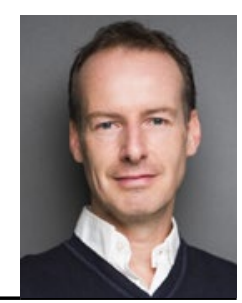

MMW: Fördern Fidget Spinner bei Schulkindern die Konzentration, wie die Hersteller behaupten, oder bewirken sie eher das Gegenteil?

Möller: Das Vorgängermodell wurde in den USA für Kinder mit Aufmerksamkeitsstörungen entwickelt. Man geht davon aus, dass es die innere Anspannung lindert, wenn man etwas in der Hand hat, worauf man herumkneten oder das man drehen kann. Weder bei ADHS noch zur Förderung der Konzentration halte ich die Geräte jedoch für sinnvoll. Es gibt schon Schulen, wo sie verboten wurden, weil die surrenden Kreisel die Kinder eher vom Unterricht ablenken.

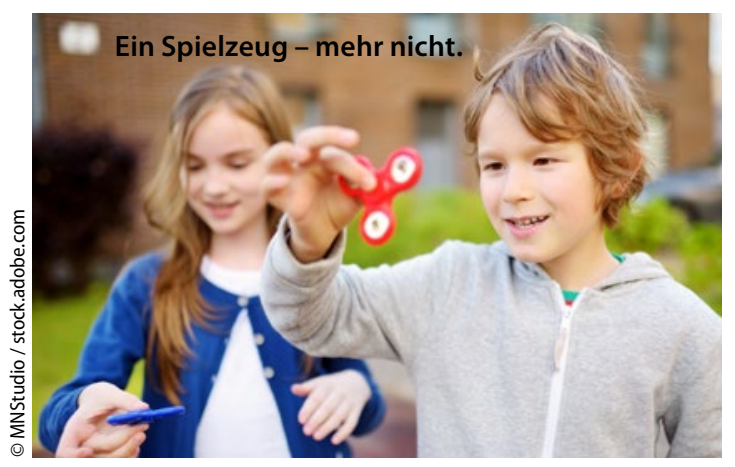

MMW: Was würden Sie empfehlen, wenn ein Kind in der Schule Schwierigkeiten hat, sich zu konzentrieren?

Möller: Erst einmal sollte man abklären, ob irgendeine behandelbare Ursache zugrunde liegt. Das kann ADHS sein, aber vor allem auch Stress zu Hause oder die Tatsache, dass die Kinder über- oder unterfordert sind. Man sollte jedenfalls nicht mit irgendwelchen Spielzeugen Versprechen abgeben, die nicht haltbar sind.

\section{MMW: Wie lässt sich die Aufmerk- samkeit fördern?}

Möller: Die Kinder kommen ja oft in die Schule, ohne sich vorher bewegt zu haben. Aus Angst, dass sie sich verletzen könnten, wenn sie zu Fuß gehen oder mit dem Fahrrad fahren, bringen die Eltern sie mit dem Auto direkt zur Schule, und dort sollen sie dann wieder stillsitzen. Man sollte viel mehr dafür sorgen, dass sich die Kinder ausreichend bewegen, weniger am Bildschirm sitzen, mehr Zeit in der Natur verbringen. Es gibt auch Ansätze wie das bewegte Klassenzimmer, wo man Bewegung in den Unterricht einbezieht. All diese Dinge sind der Konzentration viel förderlicher als so ein Spielzeug.

Interview: Dr. Elke Oberhofer

\section{Vierbeinige Schrittmacher}

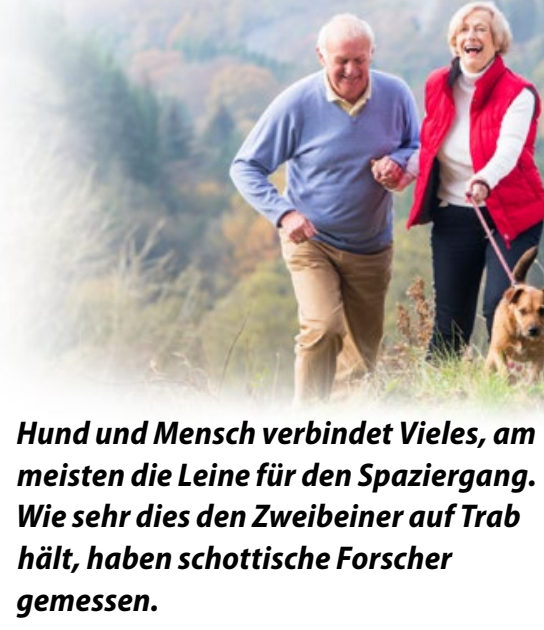

_ An ihrer Studie nahmen 43 Hundebesitzer und 43 hundelose Kontrollpersonen teil. Während eines Jahres wurde den mindestens 65 Jahre alten Probanden dreimal für eine Woche ein Akzelerometer umgeschnallt, welches das Bewegungsmuster aufzeichnete.

Für die Hundehalter ergab sich ein durchschnittliches Plus von täglich 23 gehend verbrachten Minuten - 119 vs. 96 Minuten. Das war gleichbedeutend mit 2.761 zusätzlichen Schritten: 10.030 vs. 7.269 der Kontrollgeher. Die weitere Gehstrecke wurde zudem recht zügig zurückgelegt, nämlich überwiegend mit einer Schrittfrequenz von mehr als 100/ Minute. Zudem setzten sich die Hundebesitzer signifikant seltener hin.

„Täglich 23 Minuten mäßiger bis starker körperlicher Aktivität entsprechen einer wöchentlichen Aktivität von 150 Minuten", so die Autoren. Es sei nicht verwunderlich, dass $87 \%$ der Hundebesitzer, aber nur $47 \%$ der Kontrollprobanden das empfohlene Maß an körperlicher Betätigung erfüllten. - rb 